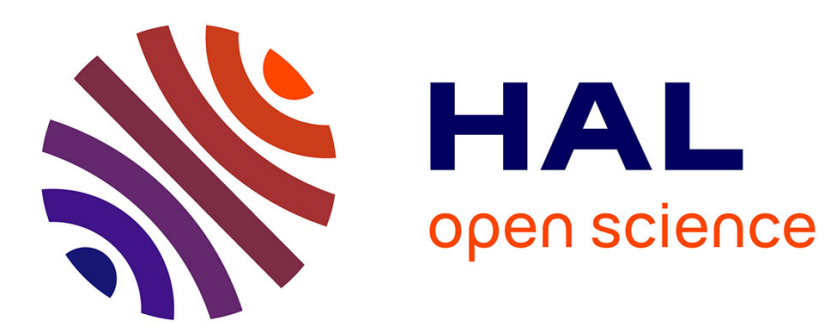

\title{
Low pressure silicon selective epitaxial growth and its thermodynamic considerations
}

\author{
L. Ye, B. Armstrong, H. Gamble
}

\section{To cite this version:}

L. Ye, B. Armstrong, H. Gamble. Low pressure silicon selective epitaxial growth and its thermodynamic considerations. Journal de Physique IV Proceedings, 1993, 03 (C3), pp.C3-51-C3-58. 10.1051/jp4:1993306 . jpa-00251363

\section{HAL Id: jpa-00251363 https://hal.science/jpa-00251363}

Submitted on 1 Jan 1993

HAL is a multi-disciplinary open access archive for the deposit and dissemination of scientific research documents, whether they are published or not. The documents may come from teaching and research institutions in France or abroad, or from public or private research centers.
L'archive ouverte pluridisciplinaire HAL, est destinée au dépôt et à la diffusion de documents scientifiques de niveau recherche, publiés ou non, émanant des établissements d'enseignement et de recherche français ou étrangers, des laboratoires publics ou privés. 


\title{
Low pressure silicon selective epitaxial growth and its thermodynamic considerations
}

\author{
L. YE, B.M. ARMSTRONG and H.S. GAMBLE
}

Institute of Advanced Microelectronics, Department of Electrical and Electronic Engineering, The Queen's University of Belfast, Belfast BT9 5 AH, United Kingdom

\begin{abstract}
In a rapid thermal processing reactor QUPLAS II, full selective epitaxial growth of silicon has been obtained using DCS in $\mathrm{H}_{2}$ without addition of $\mathrm{HCl}$. This is mainly achieved by reducing total process pressure down to the millibar regime. Selectivity can also be controlled by reducing DCS gas flow rate; however, the growth rate is greatly reduced. Process temperature has, on the other hand, a minor effect on selectivity control. The selective epitaxial growth (SEG) occurs under conditions of near thermodynamic equilibrium. Thus equilibrium partial pressures of the predominant species in the $\mathrm{Si}-\mathrm{H}-\mathrm{Cl}$ system have been calculated to give an insight into the experimental results. The availability of $\mathrm{HCl}$ species relative to silicon containing species in the gas phase, $\mathbf{P}_{\mathrm{HCl}} / \mathrm{P}_{\mathrm{Si}}$, has shown why no external $\mathrm{HCl}$ is required, for depositions in millibar regime or low DCS flow rate, to obtain full selectivity. While reaction system is near-equilibrium, the reposition of $\mathrm{Cl}$, dissociated from Si containing species, into $\mathrm{HCl}$ species, plays an important role in determining the system etching function.
\end{abstract}

\section{Introduction}

Selective epitaxial growth of silicon offers a promising technique for very large scale integration (VLSI) where device isolation is down to submicron geometry. This technique is vital for the simplification of device fabrication processes, as well as for the creation of novel device structures [1]. The basis of a SEG process is to control the deposition conditions such that single crystal growth occurs at a reasonable rate within the seed-windows, but with the etching action of $\mathrm{HCl}$, either produced from the source gas reaction or introduced from an external source, keeping the dielectric field free of polysilicon nucleii. In practice, selectivity is achieved by using the $\mathrm{SiH}_{2} \mathrm{Cl}_{2} / \mathrm{HCl} / \mathrm{H}_{2}$ chemistry at temperature between 850 $1050^{\circ} \mathrm{C}$ under reduced pressure of $10-100$ torr. Differential nucleation of silicon is normally obtained by adjusting the $\mathrm{HCl}$ flow so that the supersaturation value is sufficient for silicon nucleation over silicon but insufficient for deposition over dielectric field.

In the past few years, a considerable amount of research effort has been expended to achieve effective selectivity control without addition of external $\mathrm{HCl}$. The approaches for obtaining selectivity control, however, are different. S. K. Lee [2] has reported that excellent selectivity can be achieved without adding any $\mathrm{HCl}$ as long as the DCS volume concentration is kept below $2 \%$. An ultraclean system equipped with load-lock and hydrogen purifier was used by T. O. Sedgweck et al. [3] to selectively deposit epitaxial silicon using $\mathrm{DCS} / \mathrm{H}_{2}$ at atmospheric pressure. J. L. Regolini et al. [4] have demonstrated that the selective epitaxial growth of silicon can be achieved at reduced pressure of 2 torr 
in the temperature range of $650^{\circ} \mathrm{C}-1100^{\circ} \mathrm{C}$ using only $\mathrm{SiH}_{2} \mathrm{Cl}_{2}$ diluted in hydrogen.

The equilibrium partial pressure is one of the most important thermodynamic parameters for the study of a CVD process. Evaluation of equilibrium partial pressures can provide information on the relative proportion of each species present in an epitaxial system even if the system is not permitted experimentally to reach equilibrium. From the thermodynamic standpoint, selective epitaxial growth of silicon occurs only when reaction system state is thermodynamically near equilibrium. The system supersaturation is kept at very low degree. Thermodynamic analysis for silicon SEG is of unique importance since the process is the closest to equilibrium state of all CVD processes. Many papers have appeared in the literature which have used thermodynamically calculated equilibrium data to aid in explaining experimental results from reduction of chlorosilane. However, all available reported thermodynamic calculations are for atmospheric pressure and are not usable for the interpretation of LPCVD of silicon. In addition, the focus of previous calculations was placed on silicon growth rate and deposition efficiency. However, this is insufficient for the study of SEG silicon since differential silicon growth is largely dependent upon the availability of $\mathrm{HCl}$ species in the gas phase.

In this paper, the results of the experimental determination of selectivity control achieved by low pressure (millibar regime) growth, or by low DCS flow growth in DCS/ $\mathrm{H}_{2}$ chemistry, or by adding external $\mathrm{HCl}$ into reaction, are presented. Also reported is the thermodynamic analysis performed over temperature of $1000-1400^{\circ} \mathrm{K}$, pressure of $0.5-50 \mathrm{mbar}$ and $\mathrm{Cl} / \mathrm{H}$ ratio of $10^{-2}-10^{-1}$. The thermodynamic data are then used to give an insight into the experimental results.

\section{Experimental}

The QUPLAS II reactor used in this work is a low pressure rapid thermal CVD system. The reaction chamber is a horizontally placed quartz tube with wafer heating achieved using two banks of tungsten halogen lamps with a total input power of $18 \mathrm{kw}$. The quartz chamber walls are essentially transparent to the light, thus only the wafer reaches the process temperature. When the reactor is operated at $1000^{\circ} \mathrm{C}$, the sample temperature rises at about $200^{\circ} \mathrm{C} / \mathrm{sec}$ and cools down below $200^{\circ} \mathrm{C}$ in 20 seconds. In order to prevent quartz wall heating up, forced air is used to cool both the outside of chamber wall and the lamp-banks. A two-stage mechanical rotary pump is employed to evacuate the reaction chamber, by which the base pressure achievable is $10^{-3}$ mbar. Since hydrogen takes more than $98 \%$ of total reaction gas flow, a Semigas purifier is installed to enhance input gas purity.

All substrates used in this work involve the fabrication of seed-windows in oxide layers down to the single crystal substrates. This is achieved by (1) wet thermal oxidation to grow an oxide layer of about 1 micron thickness; (2) a reactive ion etch (RIE) process to create seed-windows; and (3) growth and subsequent etching of a sacrificial oxide for surface damage removal. Ex-situ cleaning consists of two step modified RCA cleaning, with RCA-2 step leaving the substrate surface coated with a reproducible thin oxide layer preventing any further contamination before the substrate is loaded into the reaction chamber. This thin oxide is then removed in-situ through a low pressure $\mathrm{H}_{2}$ prebake, at a temperature which results in effective etching of the oxide, but which minimises the concomitant undercutting of the exposed $\mathrm{SiO}_{2} / \mathrm{Si}$ interface [5].

After loading the processing substrate, the reaction chamber is purged with hydrogen, which also serves as reducing agent and carrier gas. Processing is usually performed by initial in-situ high temperature $\left(1000^{\circ} \mathrm{C}\right)$ prebake in $\mathrm{H}_{2}$ followed by silicon deposition in a single temperature cycle. Silicon epitaxy is triggered by the smooth introduction of DCS into reactor. SIMS analysis shows that both oxygen and carbon concentration are much lower than SIMS detectable limits and oxygen depth profile does not peak at epitaxial interface [6]. SEM micrographs from SEG specimen show the oxide field completely free of polysilicon nucleii and silicon epitaxial layer to be smooth and specular everywhere. 


\section{Thermodynamical calculations}

The chemistry that concerns this work is the $\mathrm{Si}-\mathrm{H}-\mathrm{Cl}$ system. Calculations of equilibrium partial pressures of vapour species in this system basically deal with a 3-component system, where the gaseous phase is in equilibrium with the solid phase, i.e., silicon. Therefore, according to the Gibbs rule, the system has three degrees of freedom. These are pressure, temperature and a composition parameter $\mathrm{Cl} / \mathrm{H}$. This $\mathrm{Cl} / \mathrm{H}$ ratio remains constant throughout the deposition process because neither $\mathrm{Cl}$ nor $\mathrm{H}$ atoms are added to or removed from the reaction system during the deposition or etching of silicon. This value is defined by partial pressures of gases in the initially introduced mixture. In a system where gases are controlled by flow rate, like in this study, $\mathrm{Cl} / \mathrm{H}$ can be approximately determined by the ratio of DCS flow rate over hydrogen flow rate, provided that DCS and $\mathrm{H}_{2}$ are the only supplied gases.

From previous work [7], Ban and Gilbert have numerically calculated and experimentally confirmed that the predominant species in a Si-H-Cl system using DCS as input gas include $\mathrm{H}_{2}, \mathrm{HCl}, \mathrm{SiH}_{2} \mathrm{Cl}_{2}, \mathrm{SiHCl}_{3}$, $\mathrm{SiCl}_{4}, \mathrm{SiCl}_{2}, \mathrm{SiH}_{4}$, and $\mathrm{SiH}_{3} \mathrm{Cl}$. Therefore, the following six equations describe the chemical reactions of the eight species relevant to the dichlorosilane based $\mathrm{Si}-\mathrm{H}-\mathrm{Cl}$ system. Their corresponding equations for the reaction rate constants are also given;

$$
\begin{aligned}
& \mathrm{Si}(\mathrm{s})+4 \mathrm{HCl}(g) \rightarrow \mathrm{SiCl}_{4}(g)+2 \mathrm{H}_{2}(g) \ldots \ldots \ldots K_{\mathrm{SiCl}}=\frac{P_{\mathrm{SiCl}} * P_{H 2}^{2}}{a \mathrm{Si} * P_{\mathrm{HCl}}^{4}} \\
& \mathrm{Si}(\mathrm{s})+3 \mathrm{HCl}(g) \rightarrow \mathrm{SiHCl}_{3}(g)+\mathrm{H}_{2}(g) \ldots \ldots . . K_{\mathrm{SiHCl3}}-\frac{\boldsymbol{P}_{\mathrm{SiHCl}} * \boldsymbol{P}_{\mathrm{H} 2}}{a \mathrm{Si} * P^{3}{ }_{\mathrm{HCl}}} \\
& \mathrm{Si}(\mathrm{s})+2 \mathrm{HCl}(\mathrm{g}) \rightarrow \mathrm{SiH}_{2} \mathrm{Cl}_{2}(g) \ldots \ldots \ldots \ldots \ldots K_{S i H 2 \mathrm{Cl2}}=\frac{P_{\mathrm{SiH} 2 \mathrm{Cl} 2}}{a \mathrm{Si} * P^{2}{ }_{H C l}} \\
& \mathrm{Si}(\mathrm{s})+\mathrm{HCl}(\mathrm{g})+\mathrm{H}_{2}(\mathrm{~g})-\mathrm{SiH} \mathrm{H}_{3} \mathrm{Cl}(\mathrm{g}) \ldots \ldots \boldsymbol{K}_{\mathrm{SiH} 3 \mathrm{Cl}}-\frac{\boldsymbol{P}_{\mathrm{SiH} 3 \mathrm{Cl}}}{a \mathrm{Si} * \boldsymbol{P}_{\mathrm{H} 2} * \boldsymbol{P}_{\mathrm{HCl}}} \\
& S i(s)+2 H C l(g) \rightarrow \mathrm{SiCl}_{2}(g)+\mathrm{H}_{2}(g) \ldots \ldots \ldots \ldots K_{S i C l 2}=\frac{P_{S i C l 2} * P_{H 2}}{a S i * P^{2}{ }_{H C l}}
\end{aligned}
$$

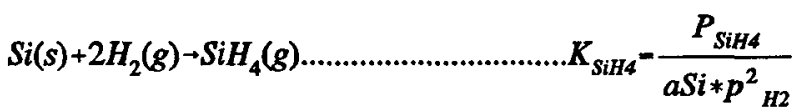

In above equations, aSi represents the activity of solid silicon; $\mathrm{aSi}=1.0$. The equations above have been formulated relating the equilibrium constant $(K)$ to equilibrium partial pressure of each species occurring in the reaction. Values of $\mathrm{K}_{\mathrm{SixHyCl}}$ at the temperature intervals of interest were calculated from thermodynamical data given in Ref.[7], which were originally evaluated by Hunt and Sirtl [8].

In order to calculate the equilibrium partial pressures of the eight species, however, one must have a set of eight independent, generally nonlinear equations, which specify relationships between species. The further two equations specify the $\mathrm{Cl} / \mathrm{H}$ ratio and state total processing pressure with respect to various partial pressures. They are;

$$
\begin{aligned}
& \frac{C l}{H}=\frac{4 P_{S i C l}+3 P_{S i H C l 3}+2 P_{S i H 2 C l 2}+2 P_{S i C l 2}+P_{S i H 3 C l}+P_{H C l}}{2 P_{H 2}+P_{S i H C l}+2 P_{S i H 2 C l 2}+3 P_{S i H 3 C l}+P_{H C l}+4 P_{S i H 4}} \\
& P_{T o t a l}=P_{S i C l 4}+P_{S i H C l 3}+P_{S i H 2 C L}+P_{S i H 3 C l}+P_{S i C l 2}+P_{S i H 4}+P_{H C l}+P_{H 2}
\end{aligned}
$$


Here, $\mathrm{Cl}$ is designated as the sum of partial pressures of all chlorine containing species. By the same token, $\mathrm{H}$ is the sum of partial pressures of pure hydrogen and hydrogen compounds. When growing $\mathrm{Si}$ from a mixture of $\mathrm{SiH}_{2} \mathrm{Cl}_{2}$ and $\mathrm{H}_{2}$, partial pressures of all other species are initially equal to zero.

Computation of the equilibrium state of the $\mathrm{Si}-\mathrm{H}-\mathrm{Cl}$ system requires the handling of general nonlinear eight variable functions. The Numerical Algorithms Group (NAG) library has been employed to solve this set of equations, finding real zeros of continuous real functions of eight variables in $\mathrm{Si}-\mathrm{H}-\mathrm{Cl}$ system. In these calculations, $\mathrm{Cl} / \mathrm{H}$ ratio was set to be $0.1,0.05,0.025$, and 0.01 ; the temperature was varied from $1000^{\circ} \mathrm{K}$ to $1400^{\circ} \mathrm{K}$, in increments of $200^{\circ} \mathrm{K}$; and pressure was assigned from 50 mbar down to 0.5 mbar with 10 points. They are chosen corresponding to the experimental conditions.

Eight solutions were produced from each computation and collected into the output data file. As the inputs include different $\mathrm{Cl} / \mathrm{H}$, temperature, and pressure, 120 sets of outputs and $120 * 8=960$ data were generated from NAG computation. The original calculated data from the NAG were then imported to a spreadsheet database so that further data manipulations could be systematically processed. Extented data, such as silicon solubility $P_{\mathrm{Si}}$, system supersaturation $P_{\text {sup }}$ and pressure ratio of $P_{\mathrm{HCl}} / \mathrm{P}_{\mathrm{Si}}$, are essential for discussions of the thermodynamic state for differential nucleation in SEG. Output data, including original and extended data, together with the 3-component input data were constructed into a multiple dimensional database, systematically describing the chlorosilane based chemical system.

\section{Experimental results and discussion aided with thermodynamical calculations}

\subsection{Selectivity control in $\mathrm{DCS} / \mathrm{H}_{2} / \mathrm{HCl}$ system}

$\mathrm{HCl}$ has been traditionally used in epitaxial CVD for substrate preclean as well as selectivity control. Basically, selectivity can always be reached by adjusting the $\mathrm{HCl}$ flow rate, since system supersaturation value decreases with the increase of silicon solubility while $\mathrm{Si}$ solubility increases with the system $\mathrm{Cl} / \mathrm{H}$ ratio. On the atomic level, silicon nucleation over oxide occurs by the adsorption and condensation of silicon adatoms on the oxide surface. The net concentration of silicon adatoms adsorbed on oxide surface is controlled by the rates of adsorption and etching of adatoms at the surface and by the density of free surface sites available for deposition of atoms. When DCS is employed as silicon reaction source, the deposition reactions are represented by;

$$
\begin{aligned}
& \mathrm{SiH}_{2} \mathrm{Cl}_{2}(g) \neq \mathrm{SiCl}_{2}(g)+\mathrm{H}_{2}(g) \\
& \mathrm{SiCl}_{2}(g)+\mathrm{H}_{2}(g)=\mathrm{Si}(\mathrm{s})+2 \mathrm{HCl}(g)
\end{aligned}
$$

$\mathrm{HCl}$ molecules are decomposition by-products and free to etch the silicon adatoms that loosely nucleate on the oxide surface. However, it has been found that with the ordinary LPCVD (P > millibar regime), the amount of internally produced $\mathrm{HCl}$ is insufficient to have a full selectivity control. In this work, selectivity has been examined with variation of $\mathrm{HCl}$ flow as well as DCS flow at a constant deposition pressure of $5 \mathrm{mbar}$ and a temperature of $960^{\circ} \mathrm{C}$. The experimental results are given in Figure [1]. The dash line in the graph separates the growth into selective and non-selective regions and the net zerogrowth line distinguishes the growth region from the etching region. From this figure, it can be identified that for a given DCS flow, there is still quite a wide range of $\mathrm{HCl}$ flow in which positive selective growth can be obtained. This indicates that selectivity is adjustable in LPCVD system.

\subsection{Selectivity control by reducing DCS flow rate in $\mathrm{DCS} / \mathrm{H}_{2}$ system}

With no external $\mathrm{HCl}$ addition, selectivity control has to be realised through optimisation of the deposition parameters. Since supersaturation is directly associated with the partial pressure of input DCS, it was expected that the most effective way of controlling the supersaturation value was by varying DCS flow percentage in total gas flow. The results of this approach have demonstrated that 


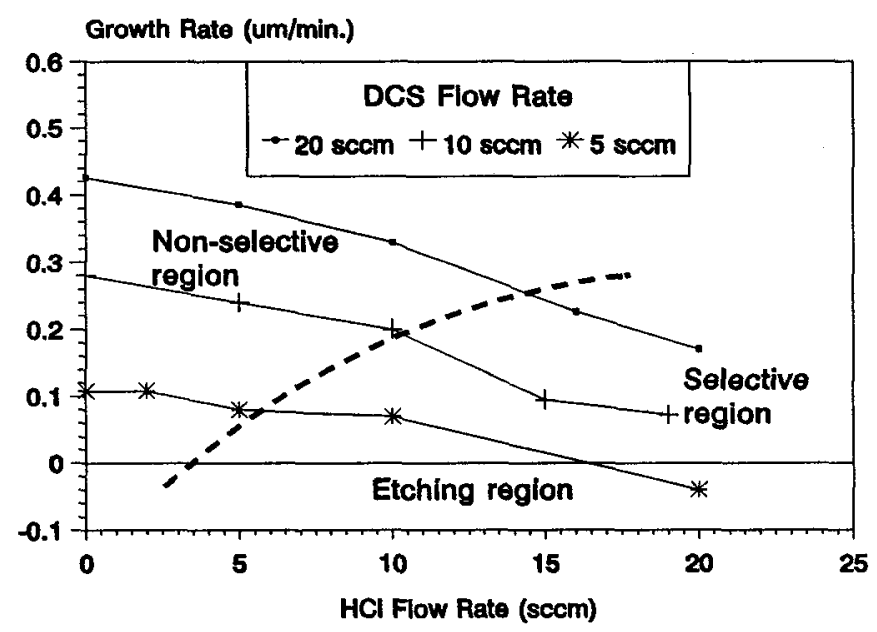

Figure 1 The dependence of growth rate on external $\mathrm{HCl}$ flow with respect to DCS flows

selectivity of SEG was gradually improved as input DCS\% flow was reduced. Complete selectivity control was achieved when the DCS flow rate was reduced to $5 \mathrm{sccm}(0.5 \%)$ in $1 \mathrm{slm} \mathrm{H}_{2}$ flow at $5 \mathrm{mbar}$ processing pressure. However, since the dependence of growth rate on DCS flow is almost linearly related in the diffusion controlled reaction regime, the grown SEG film was consequently very thin. In addition, under this approach, selectivity control was observed to be very sensitive (1) to system processing conditions, such as the cleanness of the reactor and base pressure prior to deposition, as well as (2) to substrate conditions, such as the cleaning procedure and oxide quality. Therefore, it was concluded that using low DCS flow to control selectivity was not a stable solution.

Figure [2] displays the computed results of the partial pressures of the dominant species and the pressure ratio of $\mathrm{P}_{\mathrm{HCl}} / \mathrm{P}_{\mathrm{Si}}$, with the variation of the $\mathrm{Cl} / \mathrm{H}$ ratio at a fixed temperature of $1200^{\circ} \mathrm{K}$ and a pressure of $10 \mathrm{mbar}$ at equilibrium state. It is clear that with reducing $\mathrm{Cl} / \mathrm{H}$ ratio, the partial pressures of all chlorine containing species are accordingly reducing. Consequently $\mathbf{P}_{\mathrm{H} 2}$ and $\mathrm{P}_{\mathrm{SiH} 4}$ are increasing.

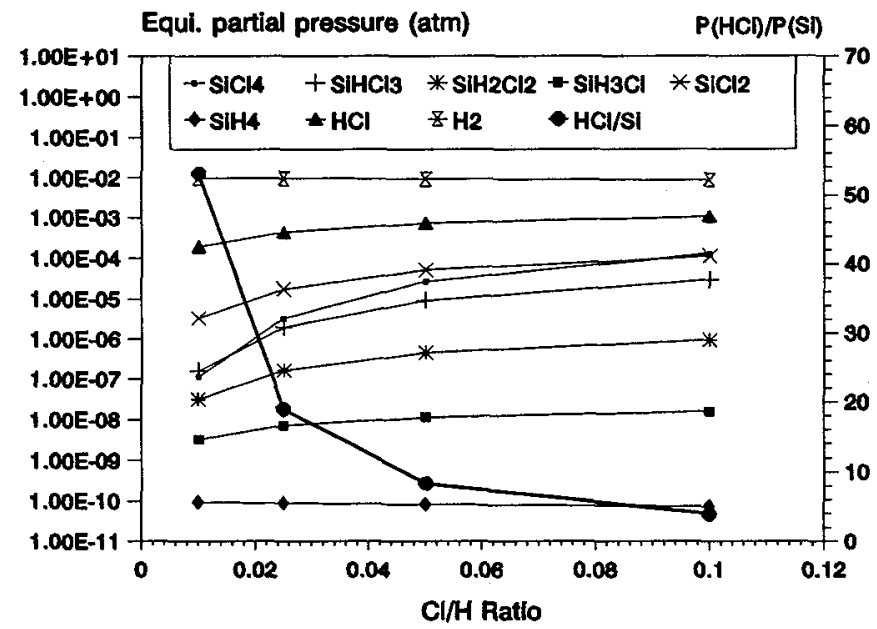

Figure 2 Calculated equilibrium state of $\mathrm{Si}-\mathrm{H}-\mathrm{Cl}$ system with respect to $\mathrm{Cl} / \mathrm{H}$ ratio in the presence of solid silicon 
However, it is important to note that the changing rates of various chlorine containing species differ significantly. The fact is that the greater the number of chlorine atoms in a species, the larger the reducing rate is. Thus, the relative importance of each species for the silicon containing gas species changes with $\mathrm{Cl} / \mathrm{H}$ ratio reduction. At the point of $\mathrm{Cl} / \mathrm{H}=0.1, \mathrm{SiCl}_{4}$ together with $\mathrm{SiCl}_{2}$ are the most dominant species in silicon containing gases. However, at the point of $\mathrm{Cl} / \mathrm{H}=0.01, \mathrm{SiCl}_{2}$ partial pressure becomes so dominant as to be about 14 times higher than that of $\mathrm{SiCl}_{4}$. From equations [9] and [10], it is understood that the dominant position of $\mathrm{SiCl}_{2}$ indicates that reactive desorption of silicon adatoms increases at that thermodynamic point.

This effect is highlighted by the pressure ratio $\mathrm{P}_{\mathrm{HCr}} / \mathrm{P}_{\mathrm{Si}},\left(\mathrm{P}_{\mathrm{Si}}\right.$ is designated to the sum of partial pressures of all silicon containing species). The ratio of $\mathrm{P}_{\mathrm{HCl}} / \mathrm{P}_{\mathrm{Sj}}$ has a slow linear increase while the $\mathrm{Cl} / \mathrm{H}$ ratio is reducing from 0.1 to 0.05 , but increases exponentially as the $\mathrm{Cl} / \mathrm{H}$ ratio reduces from 0.05 to 0.01 , indicating a high degree of $\mathrm{HCl}$ availability at low $\mathrm{Cl} / \mathrm{H}$ value operation. These theoretically calculated results suggest that the system becomes more etching reactive and good selectivity at low $\mathrm{Cl} / \mathrm{H}$ composition should be expected, as has been experimentally observed. However, since the partial pressure of silicon species at $\mathrm{Cl} / \mathrm{H}=0.01$ is decreased on one hand and etching effect is enhanced on the other hand, growth rate at this point is consequently reduced a great deal.

\subsection{Selectivity control by reducing processing pressure in $\mathrm{DCS} / \mathrm{H}_{2}$ system}

In this work, full selectivity of silicon deposition was not observed until the total processing pressure was reduced below $1 \mathrm{mbar}$ at $1035^{\circ} \mathrm{C}$. This processing pressure was reached by reducing the hydrogen carrier gas flow from $1 \mathrm{slm}$ to $300-200 \mathrm{sccm}$. Under this millibar pressure regime, the following effects have been experimentally verified;

(1) Full selectivity under millibar regime is not affected by increasing the DCS flow rate, up to $5 \%$ in total flow. This result reveals that processing pressure in the millibar regime is a much stronger factor in selectivity control than DCS flow rate.

(2) When the processing temperature is reduced, it has been found that the processing pressure required for full selectivity control needs to be slightly reduced as well.

(3) The epitaxial growth rate in this millibar regime at $1050^{\circ} \mathrm{C}$ and $2 \%$ DCS flow is about 0.1 micron per minute.

The impact of low pressure on selectivity control is presented in Figure [3], in which each gas species changing with pressure is profiled at fixed temperature of $1200^{\circ} \mathrm{K}$ and $\mathrm{C} 1 / \mathrm{H}$ ratio of 0.05 . Partial

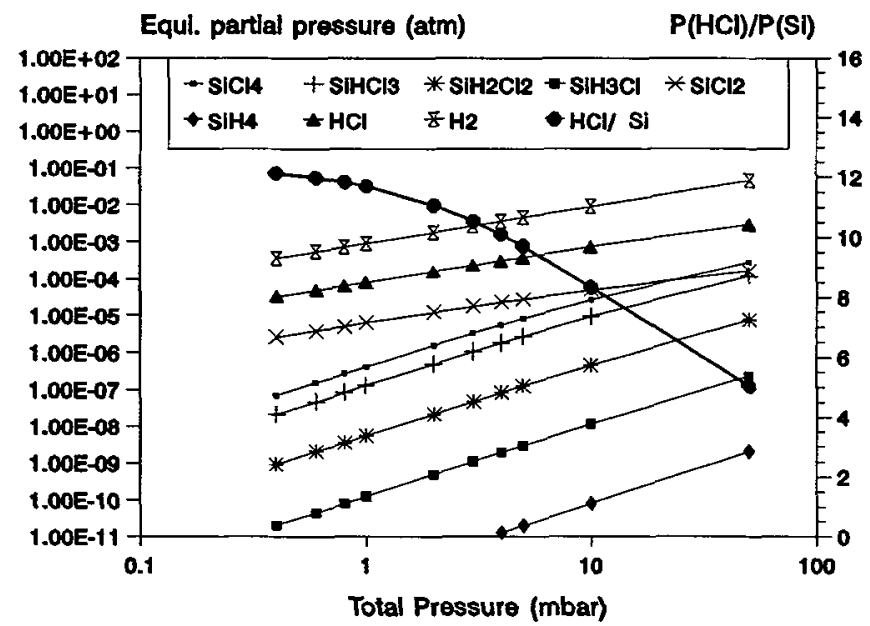

Figure 3 Calculated equilibrium state of $\mathrm{Si}-\mathrm{H}-\mathrm{Cl}$ system with respect to total pressure 
pressures of all concerning species are linearly reducing in this $\log \mathrm{P}_{\mathrm{EQUI}}$. versus $\log \mathrm{P}_{\text {TOTAL }}$ plot. They are however reducing with different rates. There are basically two groups of different reducing rate. One group consists of all silicon containing gas species except $\mathrm{SiCl}_{2}$ with high reducing rate. The other group consists of the rest of the gas species $\mathrm{H}_{2}, \mathrm{HCl}$ and $\mathrm{SiCl}_{2}$ with low reducing rate. Since no new species are generated significantly, this implies that the products of the fast reduction group will become the reactants of the slow reduction group. The effect of reducing pressure on the equilibrium composition of gas species can be explained by the decomposition of $\mathrm{SiCl}_{4}, \mathrm{SiHCl}_{3}, \mathrm{SiH}_{2} \mathrm{Cl}_{2}$ which turns out to be $\mathrm{SiCl}_{2}, \mathrm{HCl}$, and $\mathrm{H}_{2}$ when total pressure is reducing. The importance of this composition change is highlighted in $\mathrm{P}_{\mathrm{HC}} / \mathrm{P}_{\mathrm{Si}}$ profile, indicating the increased $\mathrm{HCl}$ availability in the low pressure CVD.

Experimental results show that selectivity achieved with low pressure (millibar) control is better and more stable than that with low DCS flow control. Also growth rate with the former is higher than that with the latter. Thermodynamically calculated data as listed in Table [1] provide important comparisons to aid explanation on this complex issue.

Table 1 Data comparison on selectivity between low DCS \& low pressure growth

\begin{tabular}{|c|c|c||}
\hline Process parameters & By low DCS flow & By low pressure \\
\hline \hline Temperature ${ }^{\circ} \mathrm{K}$ & 1200 & 1200 \\
\hline Pressure mbar & $1.0 \mathrm{E}+1$ & $1.0 \mathrm{E}+0$ \\
\hline $\mathrm{Cl} / \mathrm{H}$ ratio & $1.0 \mathrm{E}-2$ & $5.0 \mathrm{E}-2$ \\
\hline$\left(\mathrm{P}_{\mathrm{DCS}}\right)_{\mathrm{INPUT}} \mathrm{mbar}$ & $1.0 \mathrm{E}-1$ & $5.0 \mathrm{E}-2$ \\
\hline$\left(\mathrm{P}_{\mathrm{Si}}\right)_{\text {EQU }}$ mbar & $3.6 \mathrm{E}-3$ & $6.9 \mathrm{E}-3$ \\
\hline $\mathrm{P}_{\text {SUPERSATUR }} \mathrm{mbar}$ & $9.6 \mathrm{E}-2$ & $4.3 \mathrm{E}-2$ \\
\hline $\mathrm{P}_{\mathrm{HCI}} / \mathrm{P}_{\mathrm{Si}}$ & 53 & 11.7 \\
\hline
\end{tabular}

It can be seen that the equilibrium state reached with low DCS flow is unstable since this equilibrium point is balanced with low $\left(\mathrm{P}_{\mathrm{Si}}\right)_{\mathrm{EQU}}$ and high $\mathrm{P}_{\mathrm{HCl}} / \mathrm{P}_{\mathrm{Si}}$ ratio, the former increasing supersaturation value and the latter enhancing the etching effect. Comparatively, the equilibrium state reached with low pressure operation is characterised with high $\left(\mathrm{P}_{\mathrm{Si}}\right)_{\mathrm{EQUI}}$ and relatively low $\mathrm{P}_{\mathrm{HCl}} / \mathrm{P}_{\mathrm{Si}}$ ratio. This type of equilibrium is theoretically stable. This conclusion is in good agreement with the experimental measurements. It has also been experimentally proven that with the millibar process regime selectivity can be retained even when DCS flow increases considerably, by which growth rate can be moderately compensated. The overall comparison, thus, gives more credibility to the proposed millibar regime growth model.

\section{Discussions}

Thermodynamic calculations should in principle yield information about the composition of the partial pressures of relevant species and on the feasibility of growth and selectivity of SEG. The study of thermodynamic equilibrium state is basically a qualitative method. However, since the SEG process is so close to equilibrium state, the approximation of the actual SEG process to equilibrium state is valuable. The system $\mathrm{Si}-\mathrm{H}-\mathrm{Cl}$ is implemented in this work by a mixture of $\mathrm{DCS} / \mathrm{H}_{2}$ with or without $\mathrm{HCl}$ injection. The incoming $\mathrm{SiH}_{2} \mathrm{Cl}_{2}$ decomposes either to $\mathrm{SiCl}_{2}$ through a loss of two $\mathrm{H}$ atoms or to $\mathrm{Si}$ through a loss of two $\mathrm{HCl}$ molecules; the $\mathrm{HCl}$ created in this way reacts with the silicon deposit to form other thermodynamically stable species, such as $\mathrm{SiCl}_{4}, \mathrm{SiCl}_{3} \mathrm{H}$ and $\mathrm{SiCl}_{2}$. At a given set of conditions, temperature, pressure and $\mathrm{Cl} / \mathrm{H}$ ratio, the composition of partial pressures of all dominant species can be thermodynamically determined at equilibrium state. It has been noted from previous discussion that 
$\mathrm{Cl}$ dissociated from silicon containing species and associated into $\mathrm{HCl}$ species plays an important role since the latter determines the system etching function. The value of $\mathrm{P}_{\mathrm{HCl}}$ may not be as important as the pressure ratio $\mathrm{P}_{\mathrm{HCl}} / \mathrm{P}_{\mathrm{Si}}$ since the latter actually represents the true etching force. It is interesting to see that at certain equilibrium states where the ratio $\mathrm{P}_{\mathrm{HC}} / \mathrm{P}_{\mathrm{Si}}$ is increasing, they are also the points where $\mathrm{P}_{\mathrm{SiC2}}$ gains dominance and $\mathrm{P}_{\mathrm{SiCH}}$ and $\mathrm{P}_{\mathrm{SiHCl}}$ lose dominance. The net outcome of this dominance exchange between $\mathrm{P}_{\mathrm{SiCl} 2}$ and $\left(\mathrm{P}_{\mathrm{SiCH} 4} \mathrm{P}_{\mathrm{SiHC1} 3}\right)$ is $\mathrm{Cl}$ atom reposition from silicon species to $\mathrm{HCl}$ species. Therefore, the optimum process to achieve selectivity control is to seek high pressure ratio of $\mathrm{P}_{\mathrm{HCl}} / \mathrm{P}_{\mathrm{Si}}$, where $\mathrm{SiCl}_{2}$ is the most dominant silicon species.

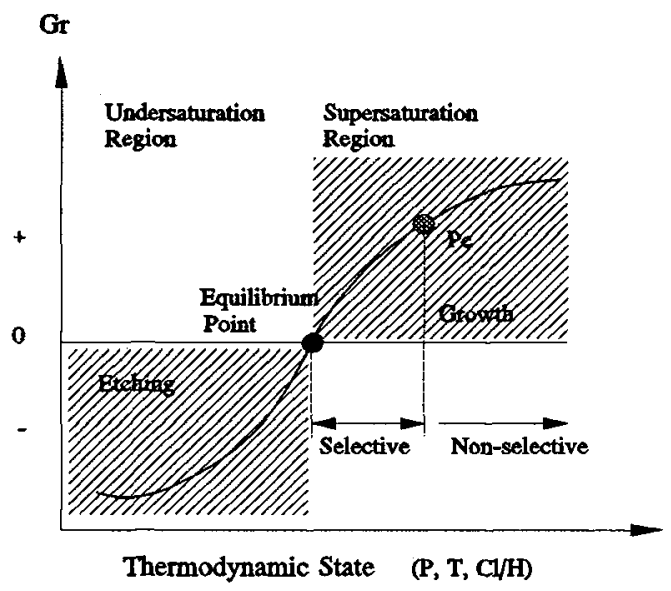

Figure 4 Near-equilibrium silicon selective epitaxial growth model

Figure [4] is drawn from the experimental findings and thermodynamic calculation conclusions, where growth rate dependence on thermodynamic state is qualitatively established. There are two domains which are referred as to growth region and etching region. The point separating these regions is the equilibrium point, where net growth rate or etching rate is virtually equal to zero. If system thermodynamic state is higher than the equilibrium point, the CVD system is supersaturated, leading to silicon deposition, and if lower than this point, the CVD system is undersaturated, leading to etching. A specific growth rate is achieved by a combination of deposition conditions which specifies a point of thermodynamic state. From the effect observed in the millibar pressure experiments, there exists a critical pressure $\left(\mathrm{P}_{\mathrm{c}}\right)$ which determines whether system is selective or non-selective in the growth region. Since $\mathrm{P}_{c}$ appears a much stronger factor on determining selectivity than $\mathrm{Cl} / \mathrm{H}$ does, the effect of $\mathrm{Cl} / \mathrm{H}$ on selectivity can be overridden if processing pressure is approaching $P_{c}$ (millibar regime). This $P_{c}$ point may change slightly with process temperature. The etching region is, however, determined by the $\mathrm{Cl} / \mathrm{H}$ ratio value. In most cases, net etching is caused only with external excessive $\mathrm{HCl}$ supply.

Acknowledgement- The author would like to thank Dr. J. L. Regolini for valuable discussion on selectivity control issues.

\section{References:}

[1] J.O. Borland and C.I. Drowley, Solid State Technology, vol. 28, no. 8, pp 141, 1985

[2] S.K. Lee et al., Appl. Phys. Lett., vol. 57, no. 3, pp 273, 1990

[3] T.O. Sedgweck et al., Appl. Phys. Lett., vol. 54, no. 26, pp 2689, 1989

[4] J.L. Regolini and D. Bensahel, Appl. Phys. Lett. vol. 54, no. 7, pp 658, 1989

[5] L. Ye et al., Proceeding of the UCPSS'92, section of Si surface passivation, Brussels, Sep. 1992

[6] D.W. McNeill, L. Ye, et al., Proceeding of EUROCVD 8, C2-779, Sep. 1991

[7] V.S. Ban and S.L. Gilbert, J. Electrochem. Soc., vol. 122, no. 10, pp 1382, 1975

[8] L.P. Hunt and E. Sirtl, J. Electrochem. Soc., vol. 119, pp 1741, 1972 